\title{
A comparative study of nature of adnexal masses by ultrasonography and histopathology MM Roshed ${ }^{1}$, MD Akhter ${ }^{2}$, SM Hossain ${ }^{3}$
}

\begin{abstract}
Background: Adnexal masses are common lesions in women across the globe. This is also important for woman in Bangladesh. The incidence of adnexal malignancy ranks only after the carcinoma of cervix and endometrium. So their accurate and early diagnosis is necessary for design management and treatment protocol.

Objective: The aim of the study is to assess the correlation between histopathological examination and ultrasonographic evaluation in making early and confirm diagnosis of adnexal masses.

Methodology: Eighty four women with different ages having adnexal mass, diagnosed by ultrasonographic evaluations and followed by surgery were included in this study between january 12 to December, 14. The morphologic characteristics of the masses were evaluated with gray scale Ultrasonography (USG). Specimens were collected after surgical resection in a container containing 10\% formalin. The specimens were processed by paraffin embedding method and stained by routine Haematoxylin and Eosin stain for microscopic examination. The results of this study were calculated by standard statistical formula.

Results: Histopathological examination revealed that 68 masses (80.95\%) were benign, two (2.38\%) were borderline malignant, and 16 (19.05\%) were malignant. USG enabled correct diagnosis of 63 of the 68 benign masses (92.65\%) and all 16 malignant masses (100\%).

Conclusion: There is a correlation between histopathological examination and ultrasonographic evaluation of adnexal masses in most cases. Therefore the imaging analysis of internal architectural appearance by USG and histopathological examination increases the specificity in the diagnosis of adnexal masses.
\end{abstract}

Key wards: Ultrasonography, Adnexal mass, Histopathology, Ovarian tumor.

\section{Introduction}

Adnexal mass refers to a mass that has grown in the uterine adnexa, which includes the tube and ovary. They can have a variety of causes, including simple ovarian cysts, benign and malignant ovarian tumors, inflammation of the fallopian tubes, as well as many other causes. ${ }^{1}$ Adnexal masses are considered as one of the common lesions in women. Moreover, the incidence of adnexal malignancy ranks after the carcinoma of cervix and endometrium. ${ }^{2}$ In 2008, the worldwide incidence of adnexal malignancy making the disease as the sixth most common malignancy among women worldwide. ${ }^{3,4}$ In spite of diagnostic and therapeutic advances in the care of women with adnexal malignancy, the overall 5 year survival rate has been changed a little. ${ }^{5-7}$ The adnexal masses often remain undiagnosed until they are large or spread to the pelvis. From the clinical presentation of adnexal mass, it is almost difficult to distinguish a benign lesion from its malignant counterpart. 8-10

Early confirmed diagnosis is very essential for any disease particularly malignancy for proper management. With the advancement of technology, the noninvasive diagnostic method such as Ultrasonogram, CT (Computed Tomography) scan and MR1 (Magnetic Resonance Imaging) have improved the diagnosis of nature of adnexal masses. ${ }^{11}$ Ultrasonographic evaluation is the most frequently applicable and easily available clinical diagnostic tool. It is an important diagnostic tool for detection of very early lesions. Histopathological

1. Md Mahabubur Roshed MPhil, Assistant Professor (Pathology), Khulna Medical College, Khulna. (E-mail: roshedm@yahoo.com)

2. Mst Dalia Akhter FCPS, Assistant Professor (Gyane \& Obs), Khulna Medical College, Khulna.

3. Syed Mozammel Hossain FCPS, Associate Professor (Surgery), Khulna Medical College, Khulna. 
examination is the most important and the gold standard means to confirm the type of masses.12 The purpose of this study was to assess the correlation between histopathological examination and ultrasonographic evaluation in making the pattern and specific diagnosis of adnexal masses.

\section{Materials and methods}

This is a cross sectional study of 84 women (aged 01-80 years; mean 32 years) with sonographically detected adnexal masses. This study was conducted at the department of Pathology, Khulna Medical College, Khulna, during the period of Ist January, 2012 to 31st December, 2014. A total number of 84 patients were included in this study. Pathological specimens were collected from Khulna Medical College Hospital and other private clinic in Khulna city. Female cases of all ages presented with adnexal mass were seen by gynecologist who underwent ultrasonographic evaluations and surgical removal, were included in this study. A detailed history of the patients was taken. Ultrasound examinations of the patients were performed transabdominally using $3.5 \mathrm{MHz}$ to $5 \mathrm{MHz}$ sector scanners with full bladder technique. The morphologic characteristics of the masses were carefully evaluated with gray scale USG, and the internal architectural details were imaged by scanning in various planes. Morphologic criteria for the diagnosis of benign and malignant masses were prospectively defined. Complex echogenicity with irregular margin are regarded as the main criteria in favour of malignant lesion. Specimens were collected after surgical resection in a container containing $10 \%$ formalin. The specimens were examined with a particular emphasis on size, shape, color, consistency, presence of capsule or not, cyst contents and appearance of cut surface. Three to five representative tissue sections of 3-5 $\mathrm{mm}$ thickness were taken from the specimen and kept in a bottle containing $10 \%$ formalin. All the sections were submitted for routine processing and paraffin embedding. Then sections were stained by routine Haematoxylin and Eosin stain for microscopic examination. Prepared sections were first examined under low power and then high power magnification. The following criteria were noted during examination: growth patterns, cellularity, and type of lining epithelium, any stratification, stromal invasion. Higher magnifications were needed to assess the degree and type of cellular differentiations, pleomorphism and also number of mitoses per 10 high power fields. Marked cellular pleomorphism and stromal invasion are main criteria for malignant lesion.
The results of this study were calculated by standard statistical formula.

\section{Result}

\section{Table I}

Age group of study population

\begin{tabular}{cc}
\hline Age group (years) & No (Percent) \\
\hline $1-10$ & $02(2.38)$ \\
$11-20$ & $11(13.10)$ \\
$21-30$ & $31(36.90)$ \\
$31-40$ & $17(20.24$ \\
$41-50$ & $12(14.29)$ \\
$51-60$ & $06(7.14)$ \\
$>60$ & $05(5.95)$ \\
\hline Total & $84(100)$ \\
\hline
\end{tabular}

This study included 84 cases. The age range was 1 to 80 years. The mean age was $30 \pm 5.23$ years. The highest incidence was found between the ages of 21 to 40 years (Table I)

\section{Table II}

Sonographic evaluation of adnexal masses

\begin{tabular}{lccc}
\hline $\begin{array}{l}\text { Type of adnexal } \\
\text { masses }\end{array}$ & $\begin{array}{c}\text { Total } \\
\text { No. (\%) }\end{array}$ & $\begin{array}{c}\text { Benign } \\
\text { No. (\%) }\end{array}$ & $\begin{array}{c}\text { Malignant } \\
\text { No (\%) }\end{array}$ \\
\hline $\begin{array}{l}\text { Ovarian tumor } \\
\text { Endometriosis }\end{array}$ & $\begin{array}{l}\text { 46(54.76) } \\
\text { Functional cyst }\end{array}$ & $27(32.14)$ & $19(22.62)$ \\
of ovary & $16(15.48)$ & $13(15.48)$ & - \\
$\begin{array}{lccc}\text { Inflamation of the } \\
\text { fallopian tube }\end{array}$ & $2(2.38)$ & $2(2.38)$ & - \\
$\begin{array}{l}\text { Ectopic pregnancies7 (8.33) } \\
7(8.33)\end{array}$ & - \\
\hline Total & $84(100)$ & $65(77.38)$ & $19(22.62)$ \\
\hline
\end{tabular}

In USG evaluation, there were 46 cases of ovarian tumor, 16 cases of endometriosis, 13 cases of functional cyst, 7 cases of ectopic pregnancy and 2 cases of inflammation of fallopian tube.

The histopathological diagnosis of 84 adnexal masses included 43 cases of ovarian tumor, 16 cases of functional cyst, 14 cases of endometriosis, 7 cases of ectopic pregnancy and 4 cases of inflammation of fallopian tube.

Comparison between Sonographic and Histopathological findings of adnexal masses of ovarian origin: In this study $75(89.29 \%)$ cases were correctly diagnosed by ultrasonographic evaluation 
out of 84 cases. The relative frequencies of benign and malignant adnexal masses were $80.95 \%$ and $19.05 \%$ respectively. The average age was $30 \pm 5.23$ years and the highest incidence was found in 21 to 40 years.

\section{Table III}

Histopathological diagnosis of adnexal masses

\begin{tabular}{lcccc}
\hline $\begin{array}{l}\text { Type of adnexal } \\
\text { masses }\end{array}$ & $\begin{array}{c}\text { Number } \\
(\%)\end{array}$ & $\begin{array}{c}\text { Benign } \\
\text { No }(\%)\end{array}$ & $\begin{array}{c}\text { BorderlineMalignant } \\
\text { No }(\%)\end{array}$ & No (\%) \\
\hline $\begin{array}{l}\text { Ovarian origin } \\
\text { Ovarian tumor }\end{array}$ & $43(51.19)$ & $25(29.76)$ & $2(2.38) 16(19.05)$ \\
$\begin{array}{l}\text { Endometriosis } \\
\text { Functional cyst }\end{array}$ & $16(16.67)$ & $14(16.67)$ & - & - \\
$\begin{array}{l}\text { Fallopian tube origin } \\
\text { Inflammation of } \\
\text { fallopian tube }\end{array}$ & $4(4.76)$ & $4(19.05)$ & - & - \\
$\begin{array}{l}\text { Ectopic } \\
\text { pregnancies }\end{array}$ & $7(8.33)$ & $7(8.33)$ & - & - \\
\hline Total & $84(100)$ & $66(78.57)$ & $2 .(2.38) 16(19.05)$ \\
\hline
\end{tabular}

Sensitivity, specificity, accuracy, positive predictive value and negative predictive value of ultrasonography were determined by comparing with final histopathological diagnosis. Ultrasonography in evaluation of nature and type of adnexal masses had sensitivity-88\%, specificity$91 \%$, accuracy- $94 \%$, positive predictive value- $83 \%$ and negative predictive value- $96 \%$.

\section{Table IV}

Comparison between sonography and histopathology findings of adnexal masses.

\begin{tabular}{lcc}
\hline Findings & $\begin{array}{c}\text { Ultrasonographic } \\
\text { No }(\%)\end{array}$ & $\begin{array}{c}\text { Histopathological } \\
\text { No }(\%)\end{array}$ \\
\hline $\begin{array}{l}\text { Ovarian tumor } \\
\text { Endometriosis }\end{array}$ & $\begin{array}{c}45(33.57) \\
\text { Cysts arising from }\end{array}$ & $\begin{array}{c}39(46.43) \\
\text { normal ovarian }\end{array}$ \\
$\begin{array}{l}\text { functions } \\
\text { Inflammation of }\end{array}$ & $13(15.48)$ & $16(16.67)$ \\
the fallopian tube & $2(2.38)$ & $6(7.14)$ \\
Ectopic pregnancies & $7(8.33)$ & $7(8.33)$ \\
Metastatic & $1(1.19)$ & $2(2.38)$ \\
\hline Total & $84(100)$ & $84(100)$ \\
\hline
\end{tabular}

\section{Discussion}

The adnexal mass is one of the most complex areas of gynecology because it gives rise to a greater range and variety of tumors than does any other organs. ${ }^{13}$ There are numerous types of adnexal masses, both benign and malignant. About $80 \%$ are benign and these are mostly in young women between the ages of 20 and 40 years. The malignant masses are more common in older women between the ages of 40 and 65 years. ${ }^{14}$

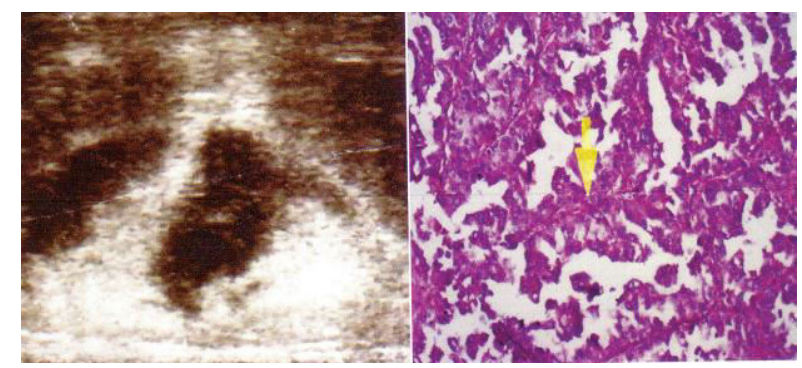

Figure 1. Papillary serous ovarian carcinoma in a $67-$ year-old woman. USG image and photomicrograph $(\mathrm{H} \& \mathrm{E}$ $\mathrm{X} 20)$.

Malignant adnexal masses getting more importance day by day as it is the second most common gynecologic malignancy among women and the second leading cause of death from gynecologic malignancy world wide. 1 Differentiation between benign and malignant adnexal masses is necessary because most of the adnexal malignancy is lethal and early diagnosis is very important. ${ }^{5}$

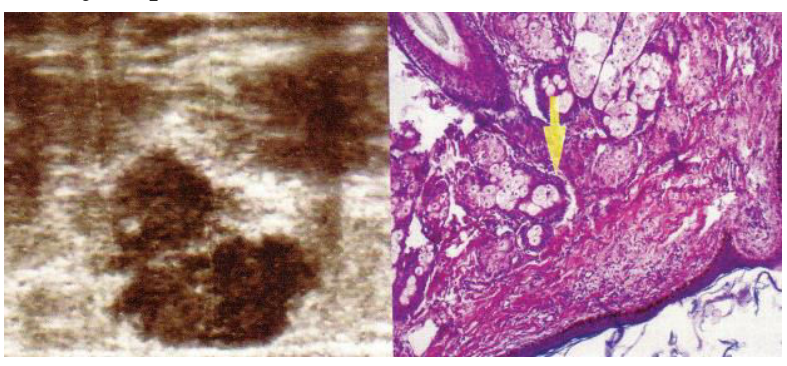

Figure 2. Mature cystic teratoma in a 31-year-old woman-USG image and photomicrograph (H\&E X 20)

During the last two decades tremendous advancement has occurred in the technology of diagnostic imaging. Ultrasonography is in front step in the development of newer generation equipment and expertise. It has excellent correlation with histologic characteristic of adnexal mass. 9 For the diagnosis of adnexal masses USG evaluation is very essential in association with an accurate medical history and careful physical examination. Accurate evaluation of adnexal masses is important for optimal treatment planning. Sonography remains the primary imaging modality for the evaluation of adnexal masses. ${ }^{10}$

Out of 84 cases, 75(92.9\%) were correctly diagnosed by ultrasonographic evaluation. The relative frequencies of benign and malignant 
adnexal masses correlate with the findings of other researchers. ${ }^{13-17}$ In the present series $80.95 \%$ were benign and $19.05 \%$ were malignant adnexal mass. Crum stated the relative incidence of all benign and malignant adnexal masses were of $80 \%$ and $20 \%$ respectively. ${ }^{2}$

The age range was 1-80 years. It was found that majority $(36.90 \%)$ belonged to the age group between 21-30 years closely followed by the group belonging to that between 31-40 years (20.24\%). Analysis of clinical features reveals that most common presenting complaints were lower abdominal pain (74.19\%). Abnormal pervaginal bleeding was in $45.24 \%$ of cases, $17.86 \%$ presented with palpable abdominal mass and $75 \%$ of both were presented with abdominal pain. Some of the patients $(17.86 \%)$ were asymptomatic and the adnexal masses were detected incidentally while an abdominal ultrasound scan was performed for other indications.

Among the adnexal masses most common ultrasonographic diagnosis was ovarian tumor and the number of cases was $46(54.77 \%)$. But histologically $43(51.19 \%)$ were confirmed as ovarian tumor. Rest of the $3(3.57 \%)$ cases, 2 were inflammation of fallopian tube and I was endometriotic cyst histologically. Ferdousi (2006) obtained $27(40.30 \%)$ cases of ovarian tumor out of 67 cases by histopathological examination and Ultrasonography correlated with 25(37.31\%) cases. ${ }^{15}$

Out of 84 cases, histopathological examination revealed 66(78.57\%) masses as benign, 2(2.38\%) cases as borderline and $16(19.05 \%)$ masses as malignant. US enabled correct diagnosis of 63 of the 66 benign masses (95.45\%). At USG 2 false negative cases were detected as benign which was diagnosed as borderline malignant tumor histologically, one borderline serous cystadenocarcinoma and another borderline endometrioid carcinoma. Benign ovarian tumor was the most common benign adnexal masses and accounted 39(46.43\%) cases of all adnexal masses and $57.35 \%$ of all benign masses. It was followed by $16(19.05 \%)$ cases of cysts arising from normal ovarian functions and $14(16.67 \%)$ cases of endometriosis. Among the benign ovarian tumors, cystadenoma was one of the common tumors. It accounted $41.17 \%$ of benign tumors and $31.8 \%$ of all ovarian tumors and most common age was between 20-50 years. The average size of the cystadenoma, usually varies from 8 to $25 \mathrm{~cm}$ in diameter. In this study the mean size of cystadenoma, was $9 \mathrm{~cm}$ and $70 \%$ of tumor ranged from $7-17 \mathrm{~cm}$. Sonographycally $84.44 \%$ benign cystic neoplasm had unilocularity or minimal septation thin wall and absence of papillary projection.

The adnexal masses arising from the fallopian tubes found in this study were 7 cases $(8.33 \%)$ of ectopic pregnancies and $2(2.38 \%)$ cases of inflammation of the fallopian tube. Sonographycally, all $7(100 \%)$ cases of ectopic pregnancies were correctly diagnosed.

Out of 19 cases of sonographycally diagnosed malignant adnexal masses, $16(88.89 \%)$ cases were proved to be accurate and 3 cases were found to be benign. The 3 false positive cases included 2 mature teratoma and I endometriosis. Sonographycally, out of 19 malignant masses, 18 were primary and I was secondary. Histologically, $14(77.78 \%)$ cases were proved as primary and $2(11.11 \%)$ cases were secondary.

In the present series the sensitivity, specificity and overall accuracy of characterization of benign and malignant adnexal masses (including the borderline tumor) of ultrasonography were $88 \%$, $91 \%$ and $94 \%$ respectively. There were 3 false positive diagnoses and 2 false negative diagnoses. This study was done on a limited number of patients with no scope for follow-up. A long term study with follow up finding is recommended.

\section{Conclusion:}

Ultrasonographic evaluation requires correlation with final histopathological diagnosis of adnexal masses. If ultrasonographic findings are confirmed by histopathological examination, the accurate diagnosis can be made on which clinicians design management and treatment protocol for the patient.

\section{References:}

1. Rubin SC, Fowler WJ Cass 1, Podratz K, Berek JS. Adnexal Mass FAQs. Gynecologic Cancer Foundation Available at: http://www.wcn.orp /interior.cfm?.htm [Accessed 30 November, 2017].

2. Crum. C.P. 'The female genital tract' in Robin and Cotran Pathologic Basis of Disease. 7th edition. Kumar V, Abbas A.K, Fausto N (Eds), Elsevier Saunders, Philadelphia.2004; pp:1083-1117.

3. Myers ER, Bastian LA, Havrilesky LJ, Kulasingam SL, Terplan MS, Cline KE, Gray RN, McCrory DC. Management of Adnexal Mass. Durham, North Carolina. AHRQ,U.S. Department of Health and Human Services, 2006.

4. Modugno F. Ovarian cancer and polymorphism in the Androgen and Progesterone receptor genes: A HUGE Review. Am J Epidemiol. 2004; 159: 319-35. 
5. Schrecengost A. Ovarian mass-benign or malignant?.ARON Journal. 2010; 78:610-29.

6. Jeong Y-Y, Outwater EK, Kang HK, Imaging Evaluation of Ovarian Masses. Radiographics.2000; 20:1445-1470.

7. Satoskar P, Deshpande A. The value of ultrasonography in the diagnosis of adnexal masses. JPostgrad Med. 2001; 37: 35-39.

8. Drake J, Diagnosis and Management of the Adnexal Mass. Am Fam Physician.Vol. 2009; 57:1-5

9. Mahfuza, K.S; Transabdominal Ultrasonographic Evaluation of Ovarian Mass (M Phil Thesis) BSMMU Dhaka, 2006.

10. Sohaib SAA, Sahdev A, Trappen PV, Jacobs IJ, Reznek RH. Am J Roentgenol 2003; 180:12971304.

11. Jain KA. Prospective Evaluation of Adnexal Masses with Endovaginal Gray-Scale and Duplex and Color Doppler US: Correlation with Pathologic Findings, Genitourinary Radiology. 2004; 191: 63-67.

12. Anderson M.C. 'Female Reproductive System' in Systemic Pathology. 5th edition, Symmers, W.St C. (ed). Churchill Livingstone, New York, 2001; 6: 241409.
13. Aure J., Hqeg C. Clinical and histologic studies of ovarian carcinoma. J. Obstet. Gynecol 2009; 37: 19.

14. Bennington. J. L, Ferguson B.R, and Haber S.L Incidence and relative frequency of benign and malignant ovarian neoplasm. Obstet. Gynecol 2008; 32:627-632.

15. Dutta A.K. Essentials of Human Anatomy. 6th edition. Current books international, Calcutta 2004; pp:361-66.

16. Ferdousi F. Clinicopathological Study of Ovarian Tumor. Dhaka, BSMMU. (M Phil Thesis), 2006.

17. Guyton A.C, Hall JE. Textbook of Medical physiology 10th edition. Bangalore. Prism books.2000; pp:786790.

18. Young R.H., Clement P.B, Scully R.E., 'The ovary' in Diagnostic Surgical Pathology. 4th edition. Sternberg S.S., Antonioli D.A.,Carter D., Mills S.E and Oberman H.A(eds). Lippincott Willams and Willkins, Philadelphia. 2004; Vol.2.pp: 2307-2413. 